\title{
Depressive Symptoms and Unmitigated Communion in Support Providers
}

\author{
LIHUA JIN ${ }^{1 *}$, NICO W. VAN YPEREN ${ }^{2}$, \\ ROBBERT SANDERMAN ${ }^{1}$ and MARIËT HAGEDOORN ${ }^{1}$ \\ ${ }^{1}$ Department of Health Sciences, University Medical Center Groningen, \\ University of Groningen, the Netherlands \\ ${ }^{2}$ Department of Social and Organizational Psychology, University of Groningen, the Netherlands
}

\begin{abstract}
In this research, we argue and demonstrate that the association between enacted (un)supportive behaviour and depressive symptoms is a function of the providers' levels of unmitigated communion (UC). UC is characterized by overinvolvement in others' problems, self-neglect and externalized self-evaluation. These characteristics appear to predispose individuals high in UC to experience depressive symptoms. As anticipated, we show that enacted supportive behaviour was negatively associated with depressive symptoms (Study 1 and 2), and enacted unsupportive behaviour was positively associated with depressive symptoms (Study 2), but only among individuals low in UC. Our findings are consistent with the idea that for high UC individuals, enacting supportive behaviour, or not enacting unsupportive behaviour, is insufficient to reduce their high levels of depressive symptoms. Copyright (C) 2009 John Wiley \& Sons, Ltd.
\end{abstract}

Key words: unmitigated communion; supportive behaviour; unsupportive behaviour; support provider; social support; psychological wellbeing

\section{INTRODUCTION}

Supportive actions, such as buying groceries for an ill partner or taking time to talk to a stressed friend, may not only alleviate depression in the person being supported but can also have an impact on the person providing the support. However, compared to the large body of research on depressive symptoms in support recipients, the number of studies of depressive symptoms in support providers is limited. The goal of this research was to gain greater insight into the association between enacted support and depressive symptoms in support providers.

\footnotetext{
*Correspondence to: Lihua Jin, Health Psychology Section, Department of Health Sciences, University Medical Center Groningen, University of Groningen, P.O. Box 196, 9700 AD Groningen, the Netherlands.

E-mail: 1.jin@med.umcg.nl
} 


\section{ENACTED SUPPORT AND THE PROVIDER'S DEPRESSIVE SYMPTOMS}

Providing support to someone in need is typically regarded as a positive experience (Carey, Oberst, McCubbin, \& Hughes, 1991; Folkman, Chesney, \& Christopherrichards, 1994; Nijboer, Tempelaar, Sanderman, Triemstra, Spruijt, \& Van den Bos, 1998; Oberst, Thomas, Gass, \& Ward S.E., 1989). By giving support to others, providers may enhance their selfimage (Riessman, 1965), improve their sense of self-worth (Luks, 1988), and increase their perception of being needed and important (Knoll, Kienle, Bauer, Pffueller, \& Luszczynska, 2007). In turn, this may bolster their self-esteem and increase their well-being. In line with this, a number of studies have identified a negative link between enacted support and providers' negative emotions, such as depressive symptoms. For example, studies of couples revealed that partners who gave support to their spouses reported a less negative mood compared to those who did not provide support (Gleason, Iida, Bolger, \& Shrout, 2003; Knoll et al., 2007). Similarly, elderly people who supported others reported higher levels of mental health than those who did not provide support (Schwartz, Meisenhelder, Ma, \& Reed, 2003). Also studies of community members showed that people who were helpful towards others through volunteer work experienced less distress than those who were not helpful (Hunter \& Linn, 1981; Musick \& Wilson, 2003; Rietschlin, 1998; Thoits $\&$ Hewitt, 2001). However, some exceptions can be found in studies of couples showing a positive association between enacted support and distress if the support recipients were seriously ill (Coyne \& Smith, 1991; Ingersoll-Dayton \& Raschick, 2004) or if the support was provided over an extended period of time (Windsor, Anstey, \& Rodgers, 2008). Some studies of older adults revealed no direct link between support and depressive symptoms if support was provided through formal organizations or training programs (Brunier, Graydon, Rothman, Sherman, \& Liadsky, 2002; Krause, Herzog, \& Baker, 1992). Situational factors, such as settings of helping, duration and intensity of care, and the relationship between providers and recipients, may play an important role in explaining differences in the support-depressive symptoms association across studies (Clark \& Reis, 1988; Nijboer, Triemstra, Tempelaar, Sanderman, \& Van den Bos, 1999; Schwartz et al., 2003; Windsor et al., 2008). Despite these differences, we agree with Post's (2005) overall conclusion that '... a strong correlation exists between the well-being, happiness, health and longevity of people who are emotionally and behaviourally compassionate, so long as they are not overwhelmed by helping tasks' (p. 66).

This paper focuses on individual differences in the strength of the association between enacted support and depressive symptoms within populations. In general, providing support to others appears to be associated with lower levels of depressive symptoms in support providers. However, this association may not be evenly distributed within populations; for some people the association may be stronger than for others. We argue and demonstrate that a personality characteristic labelled unmitigated communion (UC) plays a moderating role in the association between enacted support and depressive symptoms in support providers. In doing so, we focus on daily enacted support in close relationships.

\section{UNMITIGATED COMMUNION}

UC was developed from two fundamental personality dimensions first put forward by Bakan (1966), namely communion and agency. In their simplest forms, communion represents concerns about interpersonal relationships and reflects a focus on others whereas 
agency represents concerns about autonomous achievement and reflects a focus on self (Helgeson, 1994). UC is an extreme form of communion not mitigated by agency (Helgeson, 1994; Helgeson, 2003b; Helgeson \& Fritz, 1998). Accordingly, two central characteristics of the construct of UC are the tendency to subject oneself to the demands of others and the tendency to neglect oneself. In addition, UC was shown to be distinct from communion in terms of turning to others for self-evaluative information. Together these three characteristics appear to predispose individuals high in UC to experience low selfesteem and high levels of depressive symptoms (Helgeson, 2003b; Helgeson \& Fritz, 1998). Based on UC's characteristics, we will argue that enacted support will be negatively associated with depressive symptoms in low UC but not high UC individuals.

\section{MODERATING ROLE OF UNMITIGATED COMMUNION}

Based on the three characteristics of UC described above (overinvolvement in others' problems, self-neglect and externalized self-evaluation), we describe three reasons to expect that UC may modify the association between support provision and providers' depressive symptoms.

\section{Overinvolvement}

One key characteristic of UC individuals is that they tend to become overly involved in others' problems and take others' problems as their own. According the cost of caring hypothesis (Kessler, McLeod, \& Wethington, 1985), providing support may be distressing if the provider is emotionally overinvolved with the recipient. Specifically, if a provider becomes overly involved with others, a stressor or problem that occurs to someone else may be construed by high UC individuals as their own personal event. The higher the level of UC, the more likely it is that individuals overly engage in others' events and the more strongly they will be affected by others' problems. Indeed, a robust positive association exists between UC and negative adjustment indicators such as feeling too responsible for helping another person and having intrusive and frequent thoughts about others' problems (Aubé, 2008; Fritz \& Helgeson, 1998; Helgeson \& Fritz, 1999). Moreover, high UC individuals appear to be more strongly influenced by stressful events that occur to others than individuals low in UC (Helgeson, 2003b; Helgeson \& Fritz, 1998). Taken together, in high UC individuals, the positive effect of providing support may be counteracted by the intrusiveness of other's problems. Therefore, we expected support provision not to be associated with depressive symptoms in high UC individuals. By contrast, low UC individuals are less inclined to take others' problems as their own. Hence, among support providers low in UC, we expected support provision to be negatively correlated with depressive symptoms.

\section{Self-neglect}

The second reason to expect that UC may modify the association between support provision and providers' depressive symptoms is drawn from another feature of UC, namely self-neglect. The more individuals are characterized by UC, the stronger they feel responsible for others' needs and the more likely they fail to notice, attend to, or prioritize their own needs and symptoms (Helgeson, 2003b; Helgeson \& Fritz, 1998). Indeed, several 
studies have shown positive associations between UC and indicators of self-neglect, such as difficulties asserting one's needs, being exploitable, inhibiting self-expression to avoid conflict with others, acting against ones wishes and self-effacement (Buss, 1990; Fritz \& Helgeson, 1998; Helgeson \& Fritz, 1999). Furthermore, UC was found to be associated with a lack of self-care activities, including poor health behaviour in cardiac patients (Fritz, 2000; Helgeson \& Fritz, 1999) and in women with breast cancer (Helgeson, 2003a), and missing classes and not studying enough because of helping a friend in college students (Helgeson \& Fritz, 2000). Such neglecting of self represents another cost of caring (cf. Kessler et al., 1985), in that the interference of taking care of others with taking care of oneself may adversely affect support providers. Hence, in high UC individuals, the positive effect of providing support may also be counteracted by the neglect of their own needs. In other words, this process too leads to the expectation of support provision to be unrelated to depressive symptoms in high UC individuals. Again, we expected providing support to be negatively correlated with depressive symptoms in support providers low in UC because low UC individuals do not tend to neglect their own needs while helping others.

\section{Externalized self-evaluation}

The third reason to expect the moderating role of UC bears in its cognitive features that are key to self-esteem. As mentioned above, UC has been found to be characterized by relatively low esteem of the self (e.g. Fritz, 2000; Fritz \& Helgeson, 1998; Helgeson, 2003b; Helgeson \& Fritz, 1998, for a review see Helgeson, 1994). According to Helgeson (2003b), this lack of a positive sense of self stems from UC persons' tendency to base their self-evaluation on what others think of them (labelled externalized self-perception by Jack and Dill, 1992). Indeed, studies of adolescents attending a pre-college programme and undergraduate students have provided empirical evidence indicating that UC was associated with judging the self against others' opinions (Fritz \& Helgeson, 1998; Hennig $\&$ Walker, 2008). Such use of externalized standards for self-evaluation is especially troublesome because UC is also related to the belief that others view the self negatively (Fritz \& Helgeson, 1998). The combination of an externalized self-evaluation and the belief that others hold negative opinions of the self may make individuals characterized by UC vulnerable to low self-esteem and subsequent depressive symptoms. For example, negative events within one's personal relationships had more emotional impact on individuals high in UC relative to individuals low in UC (Nagurney, 2008; Reynolds et al., 2006). Such events (e.g. being criticized by a friend) can be interpreted as disapproval and rejection of the self, and thus confirm the idea that one is perceived negatively by others. This can be expected to cause depressive symptoms especially in those who use others' opinions for self-evaluation (i.e. high UC individuals).

Individuals high in UC may view their helping behaviour as a way to enhance others' views of themselves (Helgeson, 1994). However, exactly because of their strong focus on others' opinions for self-evaluation and the belief that these others think negatively of them, this is unlikely to be successful. Our argument draws a parallel with the sentiment override process proposed with respect to the interpretation of spousal behaviour (Weiss, 1980). That is, the interpretation of the behaviour of one's partner depends on one's global affection or disaffection for him or her, rather than the partner's objective behaviour (For example, see Hawkins, Carrere, \& Gottman, 2002). In a similar vein, high UC individuals' positive supportive behaviour may have little success in increasing their self-esteem, and 
subsequently, in decreasing their depressive symptoms, because their overall belief that others think negatively of them will override the positive effect of their support provision. Even though a supportive act may initially reduce depressive symptoms, this is not expected to have a long lasting effect. As Helgeson (1994) has put it ' . . .the unmitigated communion individual is engaged in a struggle to increase self-esteem through relationships; because their expectations are so high, however, their goals are unattainable, and self-esteem remains low' (p. 425). Individuals low in UC, who by definition are not focused so much on the opinions of others, will focus more on internal standards of evaluation. Phrased differently, they will be inclined to judge themselves on the basis of their own behaviour rather than on what others think of them. For them, doing something good for others (i.e. supporting others) signals that they are a nice and social person. In sum, only among low UC individuals, providing support was hypothesized to be negatively related to depressive symptoms.

\section{STUDY 1}

Based on the rationale outlined above, Study 1 was designed to test the hypothesis that enacted supportive behaviour is negatively correlated with depressive symptoms among providers low in UC, but not among providers high in UC. These latter providers were hypothesized to report relatively high levels of depressive symptoms irrespective of their levels of enacted support.

\section{Method}

\section{Participants and procedure}

The participants were 87 female first-year psychology students from the University of Groningen, the Netherlands. They took part in this study in exchange for a course credit. The ages of the participants ranged from 18 to 26 , with an average of 19.59 ( $S D=1.63)$.

\section{Measurements}

$U C$ was measured with the revised Unmitigated Communion Scale (Helgeson \& Fritz, 1998). Examples are 'I often worry about others' problems' and 'I always place the needs of others above my own'. Items were answered on a five-point scale ranging from 1 (strongly disagree) to 5 (strongly agree). A single index was computed by averaging nine items within subjects, with higher scores reflecting a higher degree of UC (Cronbach's $\alpha=.74)$.

Enacted supportive behaviour was measured with the subscale Interaction of the Social Support List. Previous studies supported the validity and reliability of this instrument (Hagedoorn, Sanderman, Buunk, \& Wobbes, 2002; Van Sonderen, 1993). Participants were asked to think of a loved one (i.e. partner, friend or family member) and indicate how often they provided support to that person. Items for support provision followed the general stem 'How often do you ..... Examples of items are ' ... provide attention to him/her' and '... provide information and advice to him/her'. The six items were answered on scales ranging from 1 (rarely or never) to 4 (very often). The scores were summed and averaged within participants into a single index, with a higher score indicating a higher frequency of supportive behaviour (Cronbach's $\alpha=.77$ ).

Depressive symptoms were assessed using the Center for Epidemiologic Studies Depression Scale (CES-D, Radloff, 1977; Schroevers, Sanderman, Van Sonderen, \& 
Ranchor, 2000). The CES-D consists of twenty self-report items measuring the frequency of depressive symptoms, has good psychometric properties and is widely used in studies of community samples (Shafer, 2006). Each item was completed on a four-point scale ranging from 0 (rarely or never) to 3 (almost always). Examples are 'Last week, I felt afraid' and 'Last week, I felt lonely'. Item scores were summed within subjects into a single index, with a higher score indicating a higher level of depressive symptoms. In the current sample, the scale demonstrates good internal consistency (Cronbach's $\alpha=.92$ ).

\section{Results}

Means, standard deviations and correlations are presented in Table 1. The mean scores for UC and depressive symptoms were modest and comparable to previous studies of first-year higher education students (Beck, Taylor, \& Robbins, 2003; Fritz \& Helgeson, 1998; Nagurney, 2007). Only UC was significantly related to depressive symptoms $(r=.23)$. Specifically, the higher the UC, the more depressive symptoms the participants reported. Enacted supportive behaviour was neither associated with provider depressive symptoms nor with UC.

Hierarchical regression analysis with depressive symptoms regressed on UC, enacted supportive behaviour and their interaction was applied to test the hypothesis that enacted supportive behaviour is negatively associated with depressive symptoms only among providers low in UC. To avoid multicollinearlity between the predictors and the interaction terms, we centred the predictor variables around zero and multiplied them to form the interaction term (Aiken \& West, 1991).

The results of the regression analysis are presented in Table 2 . The initially significant main effect of UC (see also Table 1) was qualified by the significant interaction of UC and enacted supportive behaviour. In order to understand how the support-depressive symptoms relationship varies from high UC to low UC, we plotted the interaction.

Table 1. Means, standard deviations and correlations (Study 1, N=87)

\begin{tabular}{lrrrrrr}
\hline Variables & Mean & $S D$ & 1 & 2 & 3 & 4 \\
\hline 1. Age & 19.59 & 1.63 & - & & & \\
2. Unmitigated communion & 3.30 & .56 & .15 & - & & \\
3. Enacted supportive behaviour & 3.25 & .45 & .16 & .15 & - & -.04 \\
4. Depressive symptoms & 12.00 & 8.89 & .16 & $.23^{*}$ & -.04 \\
\hline
\end{tabular}

${ }^{*} p<.05$.

Table 2. Multiple regression of depressive symptoms on enacted supportive behaviour (Study 1, $N=87)$

\begin{tabular}{llrrrr}
\hline & & \multicolumn{3}{c}{ Depressive symptoms } \\
\cline { 3 - 5 } & & $\Delta R^{2}$ & $\Delta F$ & $b^{\mathrm{a}}$ & $\mathrm{SE}$ \\
\hline Step 1 & Unmitigated communion (UC) & .06 & 2.61 & 2.68 & 1.77 \\
Step 2 & Enacted supportive behaviour & & & -1.74 & 2.06 \\
\hline
\end{tabular}

${ }^{\text {a }}$ The unstandardized regression weights concern the analysis in which all main and interaction effects were entered. ${ }^{*} p<.05$. 


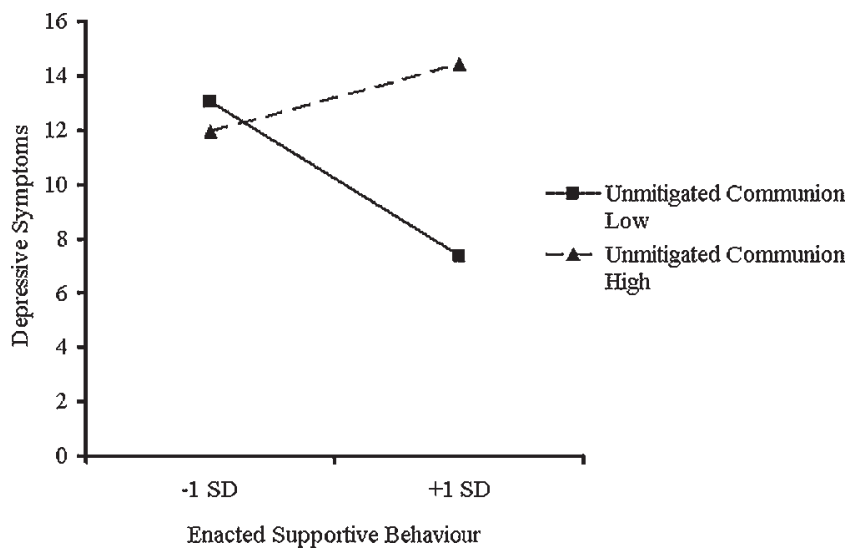

Figure 1. Interactive effect of unmitigated communion and enacted supportive behaviour on depressive symptoms (Study $1, N=87$ ).

Specifically, as suggested by Aiken and West (1991), simple regression lines of the interaction at two different levels of UC were drawn-one standard deviation above and one standard deviation below the mean-and the statistical significance of the separate slopes was calculated. The significant interaction effect of UC and enacted supportive behaviour on depressive symptoms is plotted in Figure 1. As indicated by the simple slopes, the link between supportive behaviour and depressive symptoms was significant if the providers were low in UC $(b=-6.24, p=.05)$. By contrast, among providers high in UC, supportive behaviour and depressive symptoms were unrelated $(b=2.75, p=.36)$. As hypothesized, only among low UC individuals, providing support was negatively related to depressive symptoms.

Additional tests examining the differences between predicted values of depressive symptoms showed that when the amount of enacted support was high, depressive symptoms were significantly lower in low UC individuals than in high UC individuals $(b=6.34, p<.01)$, whereas no significant difference between low and high UC individuals was observed in the case of low enacted support $(b=-.97, p=.74)$.

In sum, we found enacted supportive behaviour to be negatively associated with depressive symptoms in providers low in UC. By contrast, providers high in UC reported relatively high levels of depressive symptoms, regardless of how much support they had provided.

\section{STUDY 2}

The results of Study 1 are consistent with the idea that for high UC individuals, the act of providing support is insufficient to reduce their depressive symptoms, probably because high levels of UC override the positive feeling of doing something good. Individuals high in UC are characterized by overinvolvement in others' problems and neglect of oneself. In addition, individuals high in UC tend to use the opinions of others for self-evaluation and have a pessimistic outlook in that they believe that others do not regard them favourably (Fritz, Nagurney, \& Helgeson, 2003). We reasoned that these three characteristics (overinvolvement in others' problems, self-neglect and an externalized self-evaluation) 
may result in relatively high levels of depressive symptoms regardless of the amount of support high UC people provide. In other words, deprive them from the benefit of helping.

Although most individuals tend to help those close to them in times of stress, rather than acting supportively, individuals can act unsupportively with the best intentions. For example, they may be critical or demanding, try to avoid dispute, or minimize a problem (Dakof \& Taylor, 1990). Previous studies among partners of patients with a chronic disease have demonstrated a positive link between unsupportive behaviour (e.g. hiding worries or denying concerns, being critical) and providers' depressive symptoms (Coyne \& Smith, 1991; Hinnen, Hagedoorn, Sanderman, \& Ranchor, 2007; Suls, Green, Rose, Lounsbury, \& Gordon, 1997).

The goal of Study 2 was twofold. First, we aimed to replicate the finding of Study 1 showing that UC moderates the link between enacted supportive behaviour and depressive symptoms. The second aim was to provide more insight into the association between enacted unsupportive behaviour and depressive symptoms, and the role of UC in this association.

In contrast to support provision, which is thought to be associated with both rewards and costs (Kessler et al., 1985), acting unsupportively may be primarily associated with costs (e.g. feeling bad that one has treated someone unfairly or has been hostile). Accordingly, acting unsupportively may be positively associated with depressive symptoms. However, the positive association between enacted unsupportive behaviour and depressive symptoms may exist only among low UC individuals. In contrast, high UC individuals are characterized by overinvolvement in others' problems, self-neglect and externalized self-evaluation. As shown in Study 1, they tend to experience relatively high levels of depressive symptoms, regardless of the supportive behaviour they provide. Similarly, enacting unsupportive behaviour may not affect depressive symptoms among these individuals. Specifically, we argue that it is their overinvolvement in others' problems, self-neglect and an externalized self-evaluation rather than their supportive or unsupportive acts that determine their levels of depressive symptoms. Accordingly, we hypothesized that enacted unsupportive behaviour is positively related to depressive symptoms only among providers low in UC.

Finally, UC was traditionally introduced as a gender-related personality characteristic (Helgeson, 2003b; Helgeson \& Fritz, 1998). Although the literature is not entirely consistent, a number of studies have indeed reported sex differences in UC (Amanatullah, Morris, \& Curhan, 2008; Helgeson, Escobar, Siminerio, \& Becker, 2007; Hirokawa and Dohi, 2007; exceptions are Bruch, 2002; Helgeson, Siminerio, Escobar, \& Becker, 2009). Since the moderating effect of UC obtained in Study 1 was based on a sample including only women, we did not anticipate the moderator effect of UC to be the result of sex differences. Nevertheless, Study 2 includes both male and female participants, and therefore, we will examine the role of sex.

\section{Method}

\section{Participants and procedure}

Information about the study was posted on the university information boards and the University of Groningen intranet. Students willing to participate could access the online questionnaires by using their student accounts. In return, one out of 25 participants would win a EUR 15 gift voucher. A total of 263 students ( 206 women and 57 men) completed the online questionnaires, with an average age of $21.36(S D=2.90$, range 16-45). About 26\% of the participants were students at the Faculty of Medicine, 24\% at the Faculty of 
Behavioural and Social Sciences, about 23\% at the Faculty of Arts and Law, $16 \%$ at the Faculty of Management and Business and about $10 \%$ at the Faculty of Mathematics and the Natural Sciences. Most participants were undergraduate students $(75.3 \%)$, the rest were graduate students $(24.7 \%)$.

\section{Measurements}

UC (Cronbach's $\alpha=.72$ ), enacted supportive behaviour (Cronbach's $\alpha=.79$ ) and depressive symptoms (Cronbach's $\alpha=.85$ ) were assessed using the same questionnaires as those used in Study 1. Enacted unsupportive behaviour was measured with another subscale of the Social Support List, i.e. SSL—Negative (Hagedoorn et al., 2002; Van Sonderen, 1993). Participants were asked to think of someone close to them (the same individual when responding to the provision of support) and indicate how often they engaged in unsupportive reactions towards this person. Items were, for example 'act distant to him/her' and 'make disapproving remarks to him/her'. The seven items were answered on scales ranging from 1 (rarely or never) to 4 (very often). The scores were summed and averaged within subjects into a single index, with a higher score indicating a higher frequency of enacted unsupportive behaviour (Cronbach's $\alpha=.65$ ).

\section{Results}

The participants' mean scores for UC, enacted supportive and unsupportive behaviour, and depressive symptoms are presented in Table 3. The mean levels of UC and depressive symptoms were comparable to those found in Study 1 and other previous studies using student samples (Carton, Kessler, \& Pape, 1999; Fritz \& Helgeson, 1998; Morrison \& O’Connor, 2005; Nagurney, 2007; Seidlitz, Fujita, \& Duberstein, 2000). As in Study 1, UC was positively related to depressive symptoms $(r=.18)$, whereas enacted supportive behaviour did not show a significant correlation with depressive symptoms. Furthermore, consistent with earlier studies (Coyne \& Smith, 1991; Suls et al., 1997), enacted unsupportive behaviour was positively associated with depressive symptoms $(r=.15)$.

Age was positively associated with supportive behaviour $(r=.13)$ and negatively associated with UC $(r=-.12)$. Sex was associated with enacted supportive behaviour $(r=-.20)$, indicating that women were more likely to help others than men. There were no associations between sex and the other study variables (i.e. UC, enacted unsupportive behaviour and depressive symptoms). Furthermore, none of the study variables showed

Table 3. Correlations, means and standard deviations (Study 2, N=263)

\begin{tabular}{lrrrrrrrrrr}
\hline Variables & Mean & $S D$ & 1 & 2 & 3 & 4 & 5 & 6 & 7 & 8 \\
\hline 1. Age & 21.36 & 2.90 & - & & & & & & \\
2. Sex & -.57 & .83 & .03 & - & & & & & \\
3. Education level & 1.34 & .65 & $.38^{* * *}$ & -.01 & - & & & & \\
4. Study domain & 1.84 & .71 & .12 & .00 & $-.14^{*}$ & - & & & \\
5. Unmitigated communion & 3.20 & .58 & $-.12^{*}$ & -.08 & .01 & -.10 & - & & \\
6. Enacted supportive behaviour & 3.15 & .49 & $.13^{*}$ & $-.20^{* *}$ & .12 & .05 & $.16^{*}$ & - & \\
7. Enacted unsupportive behaviour & 1.51 & .33 & -.01 & -.02 & .00 & .08 & .10 & .03 & - \\
8. Depressive symptoms & 10.38 & 7.90 & .06 & -.08 & -.08 & .08 & $.18^{* *}$ & -.02 & $.15^{*}$ & - \\
\hline
\end{tabular}

${ }^{*} p<.05 ;{ }^{* *} p<.01 ;{ }^{* * *} p<.001$. 
significant associations with educational level (undergraduate level vs. graduate level) or study domain (science vs. social science).

A multiple regression analysis was executed to test whether UC moderates the associations between supportive and unsupportive behaviour and depressive symptoms. Given the possibility that sex might account for the function of UC in the supportdepressive symptoms association, we conducted a preliminary analysis testing two-way interactions between sex and (un)supportive behaviour. In a second preliminary analysis, sex was included as a second moderator in addition to UC. None of the two and three-way interactions including sex were significant, nor was the main effect of sex. Hence, sex was excluded in the final regression analysis presented here. We entered UC, supportive and unsupportive behaviour in the first step and the two-way interactions between UC and (un)supportive behaviour in the second step. Additional analyses were conducted to test the statistical significance of the simple slopes.

As shown in Table 4, both the main effects, and more importantly, the two-way interactions between UC and (un)supportive behaviour were found to be significant. Consistent with Study 1, UC interacted with enacted supportive behaviour in association with support providers' depressive symptoms. The plot was very similar to the one observed in Study 1 (see Figure 1). Specifically, the link between supportive behaviour and depressive symptoms was significant among low UC providers $(b=-3.16, p=.02)$, whereas supportive behaviour and depressive symptoms were unrelated $(b=1.47, p=.29)$ for providers high in UC. In other words, enacted supportive behaviour was negatively associated with depressive symptoms only among providers low in UC. Moreover, additional tests examining the differences between predicted values of depressive symptoms showed that when the amount of enacted support was high, depressive symptoms were significantly lower in low UC individuals than in high UC individuals $(b=3.92, p<.01)$, whereas no significant difference between low and high UC individuals was observed in the case of low enacted support $(b=-.05, p=.97)$.

Furthermore, the interaction between UC and enacted unsupportive behaviour was significant in which enacted unsupportive behaviour is positively associated with depressive symptoms only among providers low in UC. As displayed in Figure 2, the association between enacted unsupportive behaviour and depressive symptoms was significant if support providers scored low on UC $(b=8.08, p<.01)$, but was not significant if they scored high on $\mathrm{UC}(b=-1.87, p=.37)$. Furthermore, when the amount of enacted unsupportive behaviour was low, depressive symptoms were significantly lower among low UC individuals than in high UC individuals $(b=4.77, p<.01)$. No significant

Table 4. Multiple regression of depressive symptoms on enacted supportive behaviour, enacted unsupportive behaviour (Study 2, N=263)

\begin{tabular}{llcccr}
\hline & & \multicolumn{3}{c}{ Depressive symptoms } \\
\cline { 3 - 6 } & & $\Delta R^{2}$ & $\Delta F$ & $b^{\mathrm{a}}$ & $\mathrm{SE}$ \\
\hline \multirow{2}{*}{ Step 1 } & Unmitigated communion (UC) & .05 & 4.50 & $1.94^{*}$ & .83 \\
& Enacted supportive behaviour & & & -.84 & .96 \\
& Enacted unsupportive behaviour & & & $3.11^{*}$ & 1.43 \\
Step 2 & UC $\times$ enacted supportive behaviour & .05 & 7.34 & $4.02^{*}$ & 1.74 \\
& UC $\times$ enacted unsupportive behaviour & & & $-8.63^{* *}$ & 2.56 \\
\hline
\end{tabular}

${ }^{a}$ The unstandardized regression weights concern the analysis in which all main and interaction effects were entered. ${ }^{*} p<.05 ;{ }^{* *} p<.01$. 


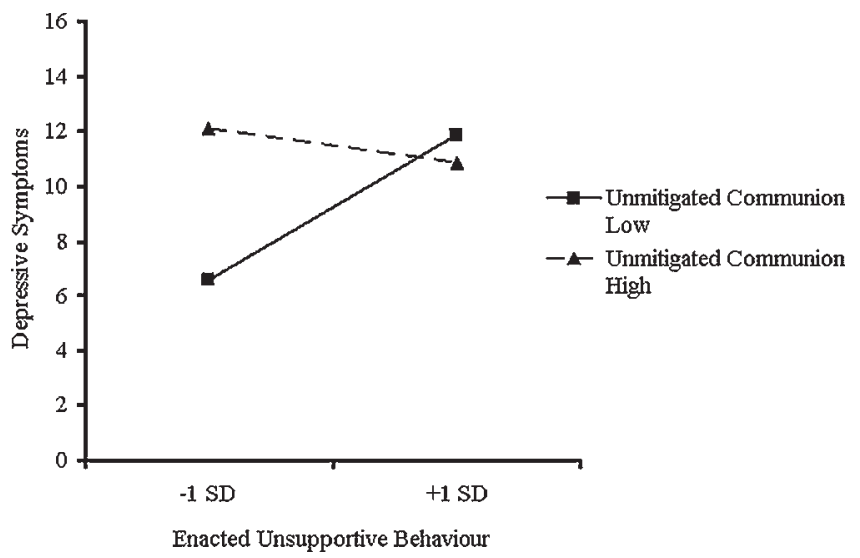

Figure 2. Interactive effect of unmitigated communion and enacted unsupportive behaviour on depressive symptoms (Study 2, $N=263$ ).

difference in terms of depressive symptoms between individuals low and high in UC was observed when the amount of enacted unsupportive behaviour was high $(b=-.89$, $p=.47)$. Therefore, depressive symptoms were particularly low among providers low in $\mathrm{UC}$ who reported relatively little unsupportive behaviour.

\section{GENERAL DISCUSSION}

The goal of this research was to gain more insight into the association between enacted supportive and unsupportive behaviour and the providers' depressive symptoms by examining the moderating role of UC. Earlier studies found that supporting others was negatively associated with providers' depressive symptoms and negative mood (Gleason et al., 2003; Knoll et al., 2007; Riessman, 1965), whereas acting unsupportively to a loved one was associated with more depressive symptoms and greater distress (Coyne \& Smith, 1991; Lakey, Tardiff, \& Drew, 1994; Suls et al., 1997). The present research extends these findings by showing that UC shapes the association between enacted supportive and unsupportive behaviours and the providers' depressive symptoms. Specifically, we found that among individuals low in UC, giving support or refraining from unsupportive behaviour was associated with less depressive symptoms. In contrast, high UC individuals tended to have high levels of depressive symptoms regardless of enacting supportive or unsupportive behaviour.

We have discussed three reasons why UC may modify the association between enacting (un)supportive behaviour and providers' depressive symptoms that are based on the three features of UC (overinvolvement in others' problems, self-neglect and an externalized selfevaluation). It is premature to draw conclusions on the plausibility of each of these three explanations, but we believe our reasoning is a good starting point for future studies to examine the underlying mechanisms of the moderating role of UC.

In addition to the main findings, it is also worth noting that UC was positively associated with depressive symptoms in both studies. These findings are consistent with previous literature showing that individuals high in UC reported greater distress and more depressive symptoms than those low in UC (Aubé, 2008; Bruch, 2002; Fritz \& Helgeson, 1998; Helgeson \& Fritz, 1999; Trudeau, Danoff-Burg, Revenson, \& Paget, 2003). 
Moreover, our studies revealed that the correlation between UC and enacted support was weak at most. Similar results have been reported by others (Fritz \& Helgeson, 2003; Helgeson \& Fritz, 1999). Although UC was conceptualized as an extreme focus on others and was associated with providing support to an ill spouse just discharged from hospital after a first coronary event (Helgeson, 1993), it appears that people high and low in UC do not differ from each other in terms of daily supportive actions. Another possible reason for the weak UC-support relation may be that high versus low UC participants assign different meanings to the answer alternatives of the supportive behaviour scale. For instance, 'very often' may mean a few times of support to someone low in UC, whereas high UC individuals may have a very high threshold for indicating this answer alternative. The different interpretations could affect participants' responses and consequently the correlation between UC and enacted supportive behaviour. Relatedly, the perceived provided support may not necessarily be in agreement with participants' actual actions. Therefore, if individuals high in UC who actually provided a great amount of support only reported to be modestly supportive to others, the positive association between UC and support could well be weakened.

To be able to evaluate the relevance of the present findings, some limitations are worth mentioning. First, due to the cross-sectional design, we cannot conclude whether enacted supportive or unsupportive behaviour affects providers' depressive symptoms or vice versa; our data do not allow any causal conclusions. We reasoned that enacted supportive behaviour protects low UC individuals from stress, whereas enacted unsupportive behaviour causes stress in low UC individual. Although the findings are consistent with such a causal model, our data can not provide empirical proof of causality. Second, this study used self-reports for all variables included, thus questions could be raised regarding self-report bias. However, in one study, self and peer reports and diary self-reports did not show differences in UC (Aubé, 2008). Given the fact that self-reported support sometimes does differ from observer-reported support (Bolger, Zuckerman, \& Kessler, 2000; Dunkel-Schetter, Blasband, Feinstein, \& Bennett, 1992), future research rating behaviour by independent observers could further increase confidence in our findings. Third, the present research was conducted with college students which may limit the generalizability of the pattern of associations found across two studies to older adult samples. Finally, the sample of Study 1 consisted of women only and the majority of the participants in Study 2 was female. Therefore, we can not provide a definite answer with respect to the role of sex.

Overall, the present research demonstrates that associations between enacted supportive and unsupportive behaviour and depressive symptoms are dependent on the providers' levels of UC. Our study is the first to examine the role of UC in the enacted supportdepressive symptoms association. Although interpretation of these results may be limited because of their correlational nature, we consider this an important first step. Below we discuss a number of suggestions for future research to increase our understanding of this issue further.

First, we theorized that (un)supportive behaviour would affect depressive symptoms in low UC individuals. However, the causal relationship could also be reversed (Moore, Underwood, \& Rosenhan, 1973; Underwood, Froming, \& Moore, 1977). An experimental design would provide more insight in the direction of causality of the link between support provision and providers' wellbeing as a function of UC. Secondly, we conducted the research in the context of young adults providing daily support (giving advices, doing activities together, comforting) to loved ones (family, friend or partner) facing general stressful situations. However, the complexity of the care task (e.g. helping to undress, 
assisting in taking a bath), the provider's social ties with the recipient (e.g. close relationship or stranger), and the severity of the recipient's problem may all influence the providers' psychological wellbeing in the course of supporting others (Clark \& Reis, 1988; Nijboer et al., 1999). For instance, a community-based study of the benefits of helping others suggested that when care tasks overwhelmed the provider, the support appeared to be negatively associated with the helper's mental health (Schwartz et al., 2003). Therefore, future research aimed at stress-specific (e.g. chronic disease) support provided in different relationships among different populations could offer an interesting extension to the current findings. Moreover, we examined the moderating role of UC with samples including predominantly women. More sex-balanced samples are needed for future studies. Finally, we have addressed and discussed several plausible interpretations of the moderating role of UC. Future studies directly investigating these psychological explanations could contribute to our understanding of why UC moderates the link between support provision and depressive symptoms, and may provide suggestions to help reduce depressive symptoms in high UC individuals.

\section{REFERENCES}

Aiken, L. S., \& West, S. G. (1991). Multiple regression: Testing and interpreting interactions. Newbury Park, London: Sage.

Amanatullah, E. T., Morris, M. W., \& Curhan, J. R. (2008). Negotiators who give too much: Unmitigated communion, relational anxieties, and economic costs in distributive and integrative bargaining. Journal of Personality and Social Psychology, 95, 723-738.

Aubé, J. (2008). Balancing concern for other with concern for self: Links between unmitigated communion, communion, and psychological well-being. Journal of Personality, 76, 101-133.

Bakan, D. (1966). The duality of human existence. Chicago: Rand Mcnally.

Beck, R., Taylor, C., \& Robbins, M. (2003). Missing home: Sociotropy and autonomy and their relationship to psychological distress and homesickness in college freshmen. Anxiety Stress and Coping, 16, 155-166.

Bolger, N., Zuckerman, A., \& Kessler, R. C. (2000). Invisible support and adjustment to stress. Journal of Personality and Social Psychology, 79, 953-961.

Bruch, M. (2002). The relevance of mitigated and unmitigated agency and communion for depression vulnerabilities and dysphoria. Journal of Counselling Psychology, 49, 449-459.

Brunier, G., Graydon, J., Rothman, B., Sherman, C., \& Liadsky, R. (2002). The psychological wellbeing of renal peer support volunteers. Journal of Advanced Nursing, 38, 40-49.

Buss, D. M. (1990). Unmitigated agency and unmitigated communion: An analysis of the negative components of masculinity and femininity. Sex Roles, 22, 555-568.

Carey, P. J., Oberst, M. T., McCubbin, M. A., \& Hughes, S. H. (1991). Appraisal and caregiving burden in family members caring for patients receiving chemotherapy. Oncology Nursing Forum, $18,1341-1348$.

Carton, J. S., Kessler, E. A., \& Pape, C. L. (1999). Nonverbal decoding skills and relationship wellbeing in adults. Journal of Nonverbal Behavior, 23, 91-100.

Clark, M. S., \& Reis, H. T. (1988). Interpersonal processes in close relationships. Annual Review of Psychology, 39, 609-672.

Coyne, J. C., \& Smith, D. A. F. (1991). Couples coping with a myocardial-infarction-A contextual perspective on wives distress. Journal of Personality and Social Psychology, 61, 404-412.

Dakof, G. A., \& Taylor, S. E. (1990). Victims perceptions of social support-What is helpful from whom. Journal of Personality and Social Psychology, 58, 80-89.

Dunkel-Schetter, C., Blasband, D. E., Feinstein, L. G., \& Bennett, H. (1992). Elements of supportive interactions: When are attempts to help effective? In S. Spacapn \& S. Oskamp (Eds.), Helping and being helped: naturalistic studies (pp. viii, 259). Newbury Park, CA: Sage Publications.

Folkman, S., Chesney, M. A., \& Christopherrichards, A. (1994). Stress and coping in caregiving partners of men with AIDS. Psychiatric Clinics of North America, 17, 35-53. 
Fritz, H. (2000). Gender-linked personality traits predict mental health and functional status following a first coronary event. Health Psychology, 19, 420-428.

Fritz, H., \& Helgeson, V. S. (1998). Distinctions of unmitigated communion from communion: Selfneglect and overinvolvement with others. Journal of Personality and Social Psychology, 75, 121-140.

Fritz, H., Nagurney, A., \& Helgeson, V. S. (2003). Social interactions and cardiovascular reactivity during problem disclosure among friends. Personality and Social Psychology Bulletin, 29, 713-725.

Gleason, M. E. J., Iida, M., Bolger, N., \& Shrout, P. E. (2003). Daily supportive equity in close relationships. Personality and Social Psychology Bulletin, 29, 1036-1045.

Hagedoorn, M., Sanderman, R., Buunk, B., \& Wobbes, T. (2002). Failing in spousal caregiving: The 'identity-relevant stress' hypothesis to explain sex differences in caregiver distress. British Journal of Health Psychology, 7, 481-494.

Hawkins, M. W., Carrere, S., \& Gottman, J. M. (2002). Marital sentiment override: Does it influence couples' perceptions? Journal of Marriage and the Family, 64, 193-201.

Helgeson, V. S. (1993). Implications of agency and communion for patient and spouse adjustment to a first coronary event. Journal of Personality and Social Psychology, 64, 807-816.

Helgeson, V. S. (1994). Relation of agency and communion to well-being: Evidence and potential explanations. Psychological Bulletin, 116, 412-428.

Helgeson, V. S. (2003a). Unmitigated communion and adjustment to breast cancer: Associations and explanations. Journal of Applied Social Psychology, 33, 1643-1661.

Helgeson, V. S. (2003b). Gender-related traits and health. In J. Suls \& K. A. Wallston (Eds.), Social psychological foundations of health and illness (pp. 367-394). Malden, MA: Blackwell.

Helgeson, V. S., Escobar, O., Siminerio, L., \& Becker, D. (2007). Unmitigated communion and health among adolescents with and without diabetes: The mediating role of eating disturbances. Personality and Social Psychology Bulletin, 33, 519-536.

Helgeson, V. S., \& Fritz, H. (1998). A theory of unmitigated communion. Personality and Social Psychology Review, 2, 173-183.

Helgeson, V. S., \& Fritz, H. (1999). Unmitigated agency and unmitigated communion: Distinctions from agency and communion. Journal of Research in Personality, 33, 131-158.

Helgeson, V. S., \& Fritz, H. (2000). The implications of unmitigated agency and unmitigated communion for domains of problem behavior. Journal of Personality, 68, 1031-1057.

Helgeson, V. S., Siminerio, L., Escobar, O., \& Becker, D. (2009). Predictors of metabolic control among adolescents with diabetes: A 4-year longitudinal study. Journal of Pediatric Psychology, 34, 254-270.

Hennig, K. H., \& Walker, L. J. (2008). The darker side of accommodating others: Examining the interpersonal structure of maladaptive constructs. Journal of Research in Personality, 42, 2-21.

Hinnen, C., Hagedoorn, M., Sanderman, R., \& Ranchor, A. V. (2007). The role of distress, neuroticism and time since diagnosis in explaining support behaviors in partners of women with breast cancer: Results of a longitudinal analysis. Psycho-Oncology, 16, 913-919.

Hirokawa, K., \& Dohi, I. (2007). Agency and communion related to mental health in Japanese young adults. Sex Roles, 56, 517-524.

Hunter, K. I., \& Linn, M. W. (1981). Psychosocial differences between elderly volunteers and nonvolunteers. International Journal of Aging \& Human Development, 12, 205-213.

Ingersoll-Dayton, B., \& Raschick, M. (2004). The relationship between care-recipient behaviors and spousal caregiving stress. Gerontologist, 44, 318-327.

Jack, D. C., \& Dill, D. (1992). The silencing the self scale-Schemas of intimacy associated with depression in women. Psychology of Women Quarterly, 16, 97-106.

Kessler, R. C., McLeod, J. D., \& Wethington, E. (1985). The costs of caring: A perspective on the relationship between sex and psychological distress. In I. G. Sarason \& B. R. Sarason (Eds.), Social support: Theory, research and applications (pp. 491-506). Dordrecht, The Netherlands: Nijhoff.

Knoll, N., Kienle, R., Bauer, K., Pffueller, B., \& Luszczynska, A. (2007). Affect and enacted support in couples undergoing in-vitro fertilization: When providing is better than receiving. Social Science \& Medicine, 64, 1789-1801.

Krause, N., Herzog, A. R., \& Baker, E. (1992). Providing support to others and well-being in later life. Journals of Gerontology, 47, 300-311.

Lakey, B., Tardiff, T. A., \& Drew, J. B. (1994). Negative social interactions-Assessment and relations to social support, cognition, and psychological distress. Journal of Social and Clinical Psychology, 13, 42-62. 
Luks, A. (1988). Helper's high. Psychology Today, 39-40.

Moore, B. S., Underwood, B., \& Rosenhan, D. L. (1973). Affect and altruism. Developmental Psychology, 8, 99-104.

Morrison, R., \& O'Connor, R. C. (2005). Predicting psychological distress in college students: The role of rumination and stress. Journal of Clinical Psychology, 61, 447-460.

Musick, M. A., \& Wilson, J. (2003). Volunteering and depression: The role of psychological and social resources in different age groups. Social Science \& Medicine, 56, 259-269.

Nagurney, A. J. (2007). The effects of relationship stress and unmitigated communion on physical and mental health outcomes. Stress and Health, 23, 267-273.

Nagurney, A. J. (2008). The effects of unmitigated communion and life events among women with fibromyalgia syndrome. Journal of Health Psychology, 13, 520-528.

Nijboer, C., Tempelaar, R., Sanderman, R., Triemstra, M., Spruijt, R., \& Van den Bos, G. (1998). Cancer and caregiving: The impact on the caregiver's health. Psycho-Oncology, 7, 3-13.

Nijboer, C., Triemstra, M., Tempelaar, R., Sanderman, R., \& Van den Bos, G. A. M. (1999). Determinants of caregiving experiences and mental health of partners of cancer patients. Cancer, $86,577-588$.

Oberst, M. T., Thomas, S. E., Gass, K. A., \& Ward, S. E. (1989). Caregiving demands and appriaisal of stress among family caregivers. Cancer Nursing, 12, 209-215.

Post, S. G. (2005). Altruism, happiness, and health: It's good to be good. International Journal of Behavioral Medicine, 12, 66-77.

Radloff, L. (1977). The CES-D scale: A self-report depression scale for research in the general population. Applied Psychological Measurement, 1, 385-401.

Reynolds, K. A., Helgeson, V. S., Seltman, H., Janicki, D., Page-Gould, E., \& Wardle, M. (2006). Impact of interpersonal conflict on individuals high in unmitigated communion. Journal of Applied Social Psychology, 36, 1595-1616.

Riessman, F. (1965). The helper therapy principle. Social Work, 10, 27-32.

Rietschlin, J. (1998). Voluntary association membership and psychological distress. Journal of Health and Social Behavior, 39, 348-355.

Schroevers, M. J., Sanderman, R., Van Sonderen, E., \& Ranchor, A. V. (2000). The evaluation of the center for epidemiologic studies depression (CES-D) scale: Depressed and positive affect in cancer patients and healthy reference subjects. Quality of Life Research, 9, 1015-1029.

Schwartz, C., Meisenhelder, J. B., Ma, Y. S., \& Reed, C. (2003). Altruistic social interest behaviors are associated with better mental health. Psychosomatic Medicine, 65, 778-785.

Seidlitz, L., Fujita, F., \& Duberstein, P. R. (2000). Emotional experience over time and self-reported depressive symptoms. Personality and Individual Differences, 28, 447-460.

Shafer, A. B. (2006). Meta-analysis of the factor structures of four depression questionnaries: Beck, CES-D, Hamilton, and Zung. Journal of Clinical Psychology, 62, 123-146.

Suls, J., Green, P., Rose, G., Lounsbury, P., \& Gordon, E. (1997). Hiding worries from one's spouse: Associations between coping via protective buffering and distress in male post-myocardial infarction patients and their wives. Journal of Behavioral Medicine, 20, 333-349.

Thoits, P. A., \& Hewitt, L. N. (2001). Volunteer work and well-being. Journal of Health and Social Behavior, 42, 115-131.

Trudeau, K. J., Danoff-Burg, S., Revenson, T., \& Paget, S. (2003). Agency and communion in people with rheumatoid arthritis. Sex Roles, 49, 303-311.

Underwood, B., Froming, W. J., \& Moore, B. S. (1977). Mood, attention, and altruism-Search for mediating variables. Developmental Psychology, 13, 541-542.

Van Sonderen, E. (1993). Het meten van sociale steun met de Sociale Steun Lijst-Interacties (SSL-I) en Sociale Steun Lijst-Discrepancies (SSL-D): Een handleiding. \{The measurement of social support with the Social Support List - Interactions (SSL-I) and Social Support List (SSl-D): A manual\}. Groningen, The Netherlands: Northern Centre for Healthcare Research, University of Groningen.

Weiss, R. L. (1980). Strategic behavioral marital therapy: Toward a model for assessment and intervention. In J. P. Vincent (Ed.), Advances in family intervention, assessment and theory (Vol I, pp. 229-271). Greenwich, CT: JAI Press.

Windsor, T. D., Anstey, K. J., \& Rodgers, B. (2008). Volunteering and psychological well-being among young-old adults: How much is too much? Gerontologist, 48, 59-70. 